\title{
Proteomic analysis of chick retina during early recovery from lens-induced myopia
}

\author{
YUN YUN ZHOU ${ }^{1-3}$, RACHEL KA MAN CHUN ${ }^{2}$, JIAN CHAO WANG ${ }^{4}$, BING ZUO $^{2}$, \\ KING KIT LI ${ }^{2}$, THOMAS CHUEN LAM ${ }^{2}$, QUAN LIU ${ }^{1,2}$ and CHI-HO TO ${ }^{1,2}$ \\ ${ }^{1}$ Refractive Surgery Department, State Key Laboratory of Ophthalmology, Zhongshan Ophthalmic Center, \\ Sun Yat-sen University, Guangzhou, Guangdong 510060; ${ }^{2}$ Laboratory of Experimental Optometry, \\ Centre for Myopia Research, School of Optometry, Hong Kong Polytechnic University, Hong Kong 999077, SAR; \\ ${ }^{3}$ Ophthalmic Center, Renmin Hospital of Wuhan University, Wuhan, Hubei 430060; ${ }^{4}$ Department of Ophthalmology, \\ The Second Affiliated Hospital of Xi'an Jiaotong University, Xi'an, Shanxi 710049, P.R. China
}

Received September 19, 2017; Accepted March 6, 2018

DOI: $10.3892 / \mathrm{mmr} .2018 .8954$

\begin{abstract}
Myopia development has been extensively studied from different perspectives. Myopia recovery is also considered important for understanding the development of myopia. However, despite several previous studies, retinal proteomics during recovery from myopia is still relatively unknown. Therefore, the aim of the present study was to investigate the changes in protein profiles of chicken retinas during early recovery from lens-induced myopia to evaluate the signals involved in the adjustment of this refractive disorder. Three-day old chickens wore glasses for 7 days (-10D lens over the right eye and a plano lens as control over the left eye), followed by $24 \mathrm{~h}$ without lenses. Protein expression in the retina was measured by two-dimensional fluorescence difference gel electrophoresis (2D-DIGE). Pro-Q Diamond phosphoprotein staining 2D gel electrophoresis was used to analyze phosphoprotein profiles. Protein spots with significant differences $(\mathrm{P}<0.05)$ were analyzed by mass spectrometry. The minus lens-treated eye became myopic, however following $24 \mathrm{~h}$ recovery, less myopia was observed. 2D-DIGE proteomic analysis demonstrated that three identified protein spots
\end{abstract}

Correspondence to: Professor Quan Liu, Refractive Surgery Department, State Key Laboratory of Ophthalmology, Zhongshan Ophthalmic Center, Sun Yat-sen University, 54S Xianlie Road, Guangzhou, Guangdong 510060, P.R. China

E-mail: drliuquan@163.com

Professor Chi-Ho To, Laboratory of Experimental Optometry, Centre for Myopia Research, School of Optometry, Hong Kong Polytechnic University, 11 Yuk Choi Road, Hong Kong 999077, SAR, P.R. China

E-mail: chi-ho.to@polyu.edu.hk

Key words: myopia recovery, retinal proteomics, Ras related protein Rab-11B, S-antigen retina and pineal gland, 26S proteasome non-ATPase regulatory subunit 14, ubiquitin carboxyl-terminal hydrolase-L1 were upregulated at least 1.2 -fold in myopic recovery retinas compared with those of the controls, Ras related protein Rab-11B, S-antigen retina and pineal gland and $26 \mathrm{~S}$ proteasome non-ATPase regulatory subunit 14 . Pro-Q Diamond images further revealed three protein spots with significant changes (at least 1.8-fold): $\beta$-tubulin was downregulated, while peroxiredoxin 4 and ubiquitin carboxyl-terminal hydrolase-L1 were upregulated in the recovery retinas compared with the control eye retinas. The present study detected previously unreported protein changes in recovering eyes, therefore revealing their potential involvement in retinal remodeling during eye ball reforge.

\section{Introduction}

Refractive errors are the result of an incorrect pairing between the axial length of an eye and its refractive power. Optical defocus inflicted to the retina results in refractive errors. Indeed, the use of negative lenses triggers hyperopic defocus and consequent axial myopia, while positive lenses on myopia defocus result in axial hyperopia (1-3). Visual signals are used to develop an emmetropization mechanism, which controls the axial elongation rate in order to locate the retina close to the focal plane (4). An emmetropic eye is one in which distant objects' images are sharply focused on the photoreceptors as a result of the perfect match between optical strengthand axial length. In contrast, a myopic eye has an axial length longer than the focal plane, resulting in an image focused in front of the retina, whilst an axial length shorter than the focal plane is typical of a hyperopic eye, in which the image is focused behind the retina. Hyperopia or myopia development is detected by the retina, triggering a signaling cascade to produce biochemical modifications via the choroid and retinal pigment epithelium (5).

Certain biomarkers could be characterized by important protein modifications such as folding change and post-translational modifications (PTM). Organisms' complexity is mainly due to PTM, mostly considered as the addition of a functional group to one or more amino acids, or the proteolytic cleavage of one or more groups (6). These 
modifications can result in several changes in protein properties $(7,8)$. The most common PTM types are glycosylation and phosphorylation, both resulting in protein function modifications. During the life cycle of the proteins, one in every three is phosphorylated (9). Phosphorylation is characterized by enzyme activity and protein signaling modifications, while glycosylation can modify regulatory functions and cell-cell identification/signaling (10). However, these important PTMs are rarely studied in myopia.

Myopia development was extensively studied from different perspectives (1,2,4-11). Myopia recovery is also considered relevant in understanding myopia and indeed several studies were performed to evaluate this aspect. For example, studies describing sclera protein profiles during development of myopia and recovery are already available $(12,13)$. Recovery from negative lens induced myopia was analyzed through the evaluation of axial elongation (14). However, as far as we know, retinal proteomics during early recovery from lens-induced myopia has not yet been reported. Therefore, in the present study we examined and mapped the proteins involved in early recovery from lens-induced myopia in chickens using two-dimensional fluorescence difference gel electrophoresis (2D-DIGE) and phosphoproteins using Pro-Q Diamond staining 2D-difference gel images. Our results underlined the validity of our approach on finding proteins which have never been previously detected and described in the retina, which could be considered as potential biomarkers in the adjustment of myopia, suggesting potential strategies to counteract it.

\section{Materials and methods}

Animals. White Leghorn chicks (Gallus gallus domesticus), hatched in an incubator, were raised in temperature-controlled brooders with water and food freely available under a $12 \mathrm{~h}$ light/12 h dark cycle (7:00 a.m.-7:00 p.m.) from the age of one day. Animal care and use were in accordance with the ARVO Statement for the Use of Animals in Ophthalmic and Vision Research. The experimental procedure and protocol were approved by the animal ethics approval committee of the Hong Kong Polytechnic University (Hong Kong, China).

Lenses and ocular measurements. All chicks were subjected to the same lens treatment and recovery conditions as described below. Initially, 34 chicks were used to monitor biometric data changes. At the end of the recovery period, four chicks were used to perform 2D-DIGE experiments, while six of them were used for Pro-Q Diamond staining 2D gel electrophoresis. Three-day old chickens wore a-10D lens in front of their right eyes and a plano lens in front of their left eyes for 7 days. These lenses were mounted on Velcro rings and glued to the feathers around the eyes. Lenses were cleaned twice every day. At the end of the 7-day period, lenses were removed for $24 \mathrm{~h}$ to allow the recovery of the right eyes. Ocular dimensions and refractive errors were measured before and after 7 days of lens wear, and again after $24 \mathrm{~h}$ recovery. Axial length is defined as the distance from the front of the cornea to the front of the retina. Ocular parameters were examined by a high-frequency A-scan ultrasound system (Manually Controlled Pulser-Receiver) with a $30 \mathrm{MHz}$ transducer (Immersion Transducers; both Olympus
Scientific Solutions Americas, Waltham, MA, USA) sampled at a rate of $100 \mathrm{MHz}$, while refractive errors were measured using a streak retinoscope (KJ6A; KangJie Co. Ltd, Jiangyan, China) as previously described (15).

Sample preparation. Once the measurements were completed, the retinal tissue was collected as previously described and frozen in liquid nitrogen (16). The frozen retinal tissue was ground in liquid nitrogen using a Teflon freezer mill (Micro-dismembrator; Braun Biotech, Melsungen, Germany) until a fine powder was obtained, which was solubilized in $300 \mu$ DIGE compatible lysis buffer containing $7 \mathrm{M}$ urea, $2 \mathrm{M}$ thiourea, $40 \mathrm{mM}$ tris, 2\% CHAPS, 1\% ASB14 and 1 tablet of Complete Mini protease (buffer for 2D-DIGE samples) or phosphatase (buffer for Pro-Q Diamond staining 2D gel electrophoresis samples) inhibitor cocktail in $10 \mathrm{ml}$ buffer (16). After centrifugation, only the supernatant was collected. The solution was then concentrated by cold $\left(-20^{\circ} \mathrm{C}\right)$ acetone precipitation over $4 \mathrm{~h}$, followed by centrifugation at $16,000 \mathrm{~g}$ at $4^{\circ} \mathrm{C}$ for $15 \mathrm{~min}$. The pellet obtained was resuspended in lysis buffer and the protein concentration was determined using a 2-D Quant kit (GE Healthcare Life Sciences, Uppsala, Sweden).

$2 D-D I G E$. Fifty micrograms of the minus lens sample and control sample were labelled with 400 pmol dye (GE Healthcare Life Sciences) on ice for $30 \mathrm{~min}$ in the dark. An internal standard (a pool made by $50 \mu \mathrm{g}$ retinal proteins from each sample) was labelled with Cy2 (Table I). All the procedures were performed in the dark, according to the protocols previously described (17-19). Isoelectric focusing (IEF) was achieved using linear immobilized $\mathrm{pH}$ gradient strips (IPG strips at a pH between 5 and 8 and $17 \mathrm{~cm}$ size; Bio-Rad Laboratories, San Diego, CA, USA). IPG strips were rehydrated at $50 \mathrm{~V}$ using Protean IEF cell (Bio-Rad Laboratories) for $12 \mathrm{~h}$ under a temperature of $20^{\circ} \mathrm{C}$ to increase protein uptake. Next, protein samples underwent IEF at $30 \mathrm{k}$ voltage/h (Vh). Next, strips were incubated in equilibration buffer (6 M urea, 30\% glycerol, $50 \mathrm{mM}$ tris and 2\% SDS, containing $0.5 \%$ DTT) for $10 \mathrm{~min}$ and they were subsequently incubated in $2 \%$ iodoacetamide for other $10 \mathrm{~min}$. Second dimension electrophoresis was then performed using $12 \%$ polyacrylamide gels between low fluorescence Pyrex glass plates in Protean II XL (Bio-Rad Laboratories) tank. Image analysis was performed using DeCyder Differential Analysis Software (DeCyder; GE Healthcare Life Sciences). The differential in-gel analysis mode was used for spot detection and quantification, and images from different gels were combined using the biological variance analysis (BVA) mode. Protein spot matching was manually confirmed for all the gels. Gels were fixed and stained with MS compatible silver stain to visualize MS spots as previously described (17) after gel analysis. The details were the following: fixation (10\% acetic acid, $40 \%$ methanol, $50 \%$ double distilled water) overnight, sensitization $(0.2 \%$ sodium thiosulfate, $30 \%$ methanol, $70 \%$ double distilled water) $30 \mathrm{~min}$, washing (double distilled water) 5 min x 3 times, silver impregnation (0.25\% silver nitrate, $100 \%$ double distilled water) $20 \mathrm{~min}$, washing (double distilled water) 1 min x 2 times, developing (2.5\% sodium carbonate, $100 \%$ double distilled water, $0.04 \%$ formaldehyde) until each protein point clearly appeared, 
Table I. CyDyes minimal labelling experiment design of retinal samples in 2D-DIGE.

\begin{tabular}{lllr}
\hline Gel no. & \multicolumn{1}{c}{ Cy2 (pool internal control) } & Cy3 (treated/control) & Cy5 (treated/control) \\
\hline Gel 1 & $\begin{array}{l}\text { Pool of all } 8 \text { eyes }(6.25 \mu \mathrm{g} \text { from both } \\
\text { eyes of each animal, total } 50 \mu \mathrm{g})\end{array}$ & No. 1 treated $(50 \mu \mathrm{g})$ & No. 1 control $(50 \mu \mathrm{g})$ \\
Gel 2 & $\begin{array}{l}\text { Pool of all } 8 \text { eyes }(6.25 \mu \mathrm{g} \text { from both } \\
\text { eyes of each animal, total } 50 \mu \mathrm{g})\end{array}$ & No. 2 control $(50 \mu \mathrm{g})$ & No. 2 treated $(50 \mu \mathrm{g})$ \\
Gel 3 & $\begin{array}{l}\text { Pool of all } 8 \text { eyes }(6.25 \mu \mathrm{g} \text { from both } \\
\text { eyes of each animal, total } 50 \mu \mathrm{g})\end{array}$ & No. 3 treated $(50 \mu \mathrm{g})$ & No. $3 \mathrm{control}(50 \mu \mathrm{g})$ \\
Gel 4 & $\begin{array}{l}\text { Pool of all } 8 \text { eyes }(6.25 \mu \mathrm{g} \text { from both } \\
\text { eyes of each animal, total } 50 \mu \mathrm{g})\end{array}$ & No. 4 control $(50 \mu \mathrm{g})$ & No. 4 treated $(50 \mu \mathrm{g})$ \\
\end{tabular}

No. 1, no. 2, no. 3 and no. 4 represent four individual chicks. 2D-DIGE, two-dimensional fluorescence difference gel electrophoresis.

stopping (5\% acetic acid, $95 \%$ double distilled water) at least for $15 \mathrm{~min}$. The differential protein expression was taken into consideration, if present, in all samples and each should show the same up- or downregulation.

Pro-Q Diamond staining 2D gel electrophoresis. One hundred microgram chick retinas samples were mixed with an equal volume of buffer containing $7 \mathrm{M}$ urea, $2 \mathrm{M}$ thiourea, $2 \%$ CHAPS, $1 \%$ ASB14, 2\% DTT, 0.4\% Biolytes and a trace amount of bromophenol blue and left on ice for $10 \mathrm{~min}$. IPG strips of $11 \mathrm{~cm}$, at a $\mathrm{pH}$ 4-7 were passively rehydrated with the samples in $200 \mu \mathrm{l}$ rehydration buffer for $12 \mathrm{~h}$. Next, IEF was performed at $100 \mathrm{~V}$ for $2 \mathrm{~h}, 500 \mathrm{~V}$ for $1 \mathrm{~h}, 1,000 \mathrm{~V}$ for $1 \mathrm{~h}, 4,000 \mathrm{~V}$ for $2 \mathrm{~h}$ and $8,000 \mathrm{~V}$ for $5 \mathrm{~h}$ under linear voltage ramp using a BioRad PROTEAN IEF Cell. Subsequently, IPG strips were incubated in equilibration buffer I (6 M urea, $30 \%$ glycerol, $50 \mathrm{mM}$ tris, $2 \% \mathrm{SDS}, 0.5 \% \mathrm{DTT}$ ) for $10 \mathrm{~min}$, and then in equilibration buffer II (6 M urea, 30\% glycerol, $50 \mathrm{mM}$ tris, $2 \% \mathrm{SDS}, 2 \%$ iodoacetamide) for $10 \mathrm{~min}$. The strips were loaded onto $12 \%$ homogenous SDS PAGE gels of $1.5 \mathrm{~mm}$ thickness and sealed with $0.5 \%$ agarose. Protein separation in the second dimension was performed at $20 \mathrm{~mA}$ per gel using an Ettan DALT (Bio-Rad Laboratories, San Diego, CA, USA).

Gels were stained with Pro-Q Diamond (Pro-Q ${ }^{\circledR}$ Diamond Phosphoprotein Gel Destaining Solution; Invitrogen; Thermo Fisher Scientific, Inc., Waltham, MA, USA) to detect phosphoproteins and imaged using $532 \mathrm{~nm}$ excitation wavelength and $560 \mathrm{~nm}$ band pass filter using Typhoon 9400 Variable Mode Imager (Amersham Biosciences; GE Healthcare Life Sciences). The image analysis was performed by Image Master Platinum, version 5 (Bioinformatics, Uppsala, Sweden). Differential protein expression was taken into consideration if present in at least 5 samples and they should show the same up- or downregulation. Silver was used to visualize the protein spots for mass spectrometry.

$L C-M S / M S$. The differentially expressed protein spots were excised and processed as previously described (17-19). Extracts were dried by Speedvac Savant (Thermo Fisher Scientific, Inc.) and dissolved in $20 \mu 10.1 \%$ formic acid. Peptides were separated using an Ultimate 3000 nano liquid chromatography system (LC Packings; Dionex, San
Francisco, CA, USA) and analyzed by HCT Ultra ion trap mass spectrometer (Bruker Daltonics, Ettlingen, Germany) equipped with an online nanospray source. Samples were injected onto a reversed-phase pre-column (300 $\mu \mathrm{m}$ i.d.; 5 mm; C18 PepMap; LC Packings; Dionex) and then eluted and separated for $10 \mathrm{~min}$ on nano reversed phase column (75 $\mu$ m i.d.; 150 mm; C18 PepMap; LC Packings; Dionex) with linear gradient from $96 \%$ mobile phase A/4\% mobile phase $\mathrm{B}$ to $50 \%$ mobile phase $\mathrm{A} / 50 \%$ mobile phase $\mathrm{B}$. Mobile phase A contained $0.1 \%(\mathrm{v} / \mathrm{v})$ formic acid in water and mobile phase B contained $0.08 \%$ formic acid in water-ACN (20:80, v/v\%). The column was connected to an electrospray emitter, distal coating, $20 \mathrm{~mm}$ i.d. with $10 \mathrm{~mm}$ opening (New Objective, Woburn, MA, USA). Peptides were detected in the positive ion mode and fragmented by collision-induced dissociation using helium as the collision gas. The voltage applied to the capillary cap was $-1,500 \mathrm{~V}$ and capillary temperature was set at $150^{\circ} \mathrm{C}$. Precursor selection was set at 300-1,500 mass-to-charge ratio $(\mathrm{m} / \mathrm{z})$. Two most abundant precursor ions were selected for MS/MS. Three scans were averaged to obtain an MS/MS mass spectrum. MS and MS/MS data were searched using NCBInr protein database (NCBIni_20081017) by MASCOT search engine, according to the following settings: trypsin was designated as the digestion enzyme and one missed cleavage was allowed. Carbamidomethylation of cysteines was set as fixed modification and oxidation of methionine residues as variable modification. The mass tolerances were 1.2 Da for MS and 0.6 Da for MS/MS. Proteins were considered identified when at least two peptides met the confident threshold of 0.05 .

Statistical analysis. 2D-DIGE protein spots with an expression change $>1.2$-fold and a value of $\mathrm{P}<0.05$ by Student's paired t-test, were defined as differentially expressed proteins and considered statistically significant (20,21). Pro-Q Diamond staining 2D-difference gel images protein spots with an expression change $>1.8$-fold and a value of $\mathrm{P}<0.05$ by Student's Paired t-test were defined as differentially expressed proteins and considered statistically significant. Results were considered statistically significant when confirmed in four (2D-DIGE) or five (Pro-Q Diamond staining) separated gels. Furthermore, a visual check on the significant spots was performed by two separated experts to 
A
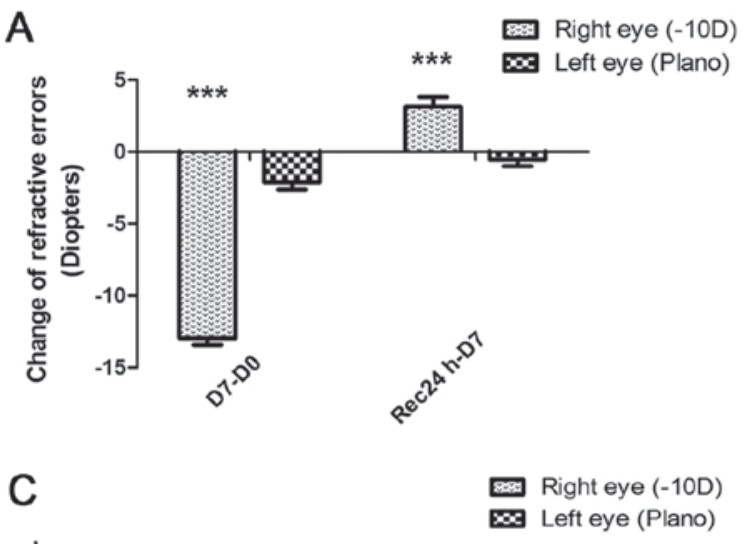

B
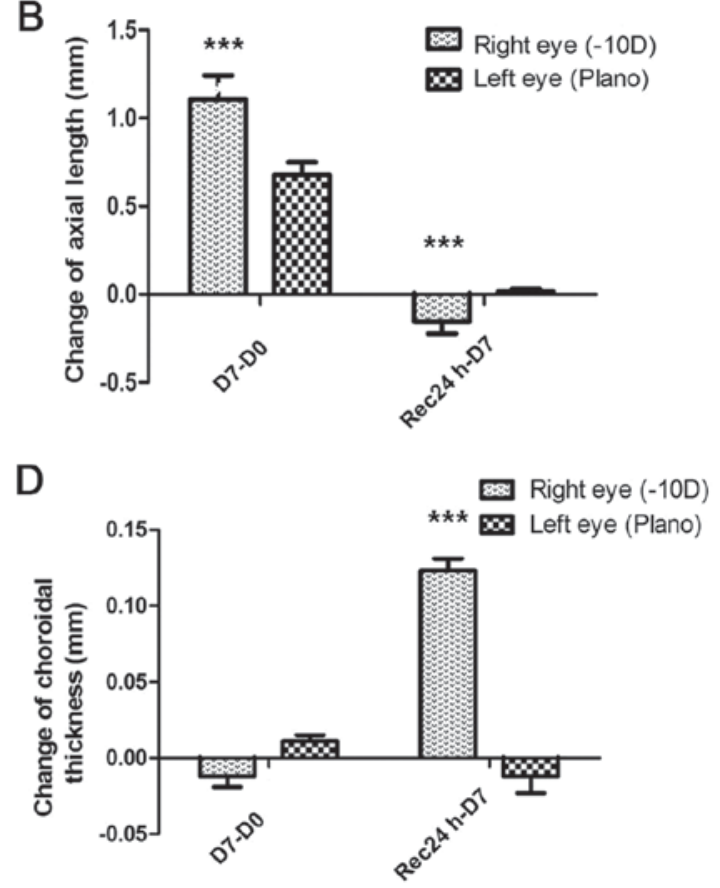

Figure 1. Effect of lens wear and recovery on (A) refractive errors; (B) axial length; (C) vitreous chamber depth; (D) choroidal thickness. Parameters' changes after 7 days lens wear (D7-D0). Parameter changes after $24 \mathrm{~h}$ of recovery (Rec24 h-D7). ${ }^{* * * *} \mathrm{P}<0.001$ vs left eye, $\mathrm{n}=34$.

confirm that they were real protein spots, instead of stripes or artifacts.

\section{Results}

Refractive and axial changes. Refractive values and axial ocular dimensions are shown in Fig. 1. After 7 days of lens wear, the treated eyes partially compensated to the presence of the lens, with the minus lens-treated eye becoming myopic (treated vs. control: $-9.44 \pm 0.54 \mathrm{D}$ vs. $1.48 \pm 0.50 \mathrm{D}$, $\mathrm{P}<0.001, \mathrm{n}=34$, Fig. 1A). After $24 \mathrm{~h}$ recovery, less myopia was observed in the treated eyes (treated vs. control: $-6.31 \pm 0.82$ D vs. $0.94 \pm 0.39 \mathrm{D}, \mathrm{P}<0.001, \mathrm{n}=34$, Fig. $1 \mathrm{~A})$. The axial length of the minus lens-treated eye was significantly longer than that of the control eye (treated vs. control: $1.32 \pm 0.22 \mathrm{~mm}$ vs. $0.70 \pm 0.23 \mathrm{~mm}, \mathrm{P}<0.001, \mathrm{n}=34$, Fig. 1B) due to the vitreous chamber enlargement (Fig. 1C). The choroid was significantly thinner in the minus lens-treated eyes than in the control eyes (Fig. 1D). During the recovery time, axial length and vitreous chamber length partly recovered their original values, while the choroid was significantly thicker than the choroid in the control eyes (Fig. 1B-D).

Differential protein expression between myopia recovery retina and control retina by $2 D-D I G E$. After gel analysis, $1,864 \pm 142$ protein spots were resolved and compared on the 2D-DIGE gels (Fig. 2). Five spots differed between the right myopia recovery group and the left control group. Five spots showed upregulation in myopic recovery retinas, and three of them were successfully identified by mass spectrometry: Ras related protein Rab-11B, S-antigen retina and pineal gland (arrestin) and 26S proteasome non-ATPase regulatory subunit 14 (PSMD14) (Table II). The other two proteins were not identified because of their very low concentration in chick retina.

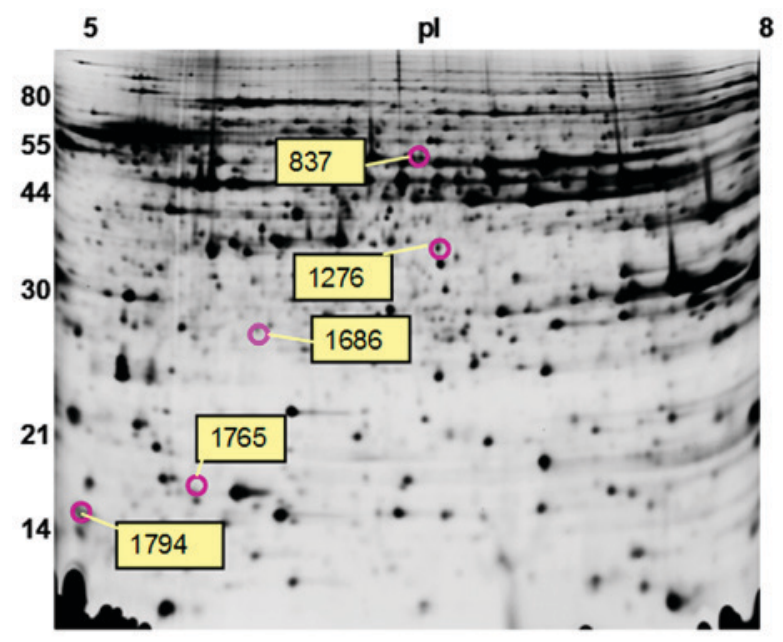

Figure 2. Identification of differential protein expression in chick retinas after minus lens wear and early recovery by 2D-DIGE. The gel image is a representative DIGE gel. Approximate molecular weights and isoelectric points are indicated. All spots represent upregulated proteins in myopic recovery retinas compared to control retinas. 2D-DIGE, two-dimensional fluorescence difference gel electrophoresis.

Differential protein expression between myopia recovery retina and control retina by Pro- $Q$ Diamond staining $2 D$ gel electrophoresis. After gel analysis, 4 spots showed a 1.8 -fold difference between the two groups. One spot was downregulated in the myopia recovery group and 3 were upregulated (Fig. 3).

Of these 4 spots of interest, 3 were successfully identified by mass spectrometry: $\beta$-tubulin, peroxiredoxin 4 and ubiquitin carboxyl-terminal hydrolaseL1 (UCHL1) (Table III). The remaining protein was not identified because of its very low concentration in chick retina. 
Table II. Differential protein expression between myopia early recovery retina and control retina in 2D-DIGE.

\begin{tabular}{ccccccccc}
\hline Spot no. & IPI no. & $\begin{array}{c}\text { Mascot } \\
\text { protein name }\end{array}$ & $\begin{array}{c}\text { Mowse } \\
\text { score }\end{array}$ & $\begin{array}{c}\text { Sequence } \\
\text { coverage (\%) }\end{array}$ & Mascot Pi & $\begin{array}{c}\text { Mascot Mw } \\
(\mathrm{kDA})\end{array}$ & $\begin{array}{c}\text { Poptides no. } \\
\text { difference }\end{array}$ \\
\hline 837 & 596741 & Arrestin & 81.45 & 5.58 & 6.33 & 46.64 & 4 & 1.20 \\
1686 & 573563 & Rab-11B & 192.46 & 33.94 & 5.57 & 46.64 & 8 & 1.24 \\
1276 & 604055 & PSMD14 & 225.45 & 16.45 & 6.00 & 34.72 & 8 & 1.23 \\
\hline
\end{tabular}

IPI, International Protein Index. 2D-DIGE, two-dimensional fluorescence difference gel electrophoresis.

Table III. Differential protein expression between myopia early recovery retina and control retina in Pro-Q Diamond staining 2D gel electrophoresis.

\begin{tabular}{lccccccc}
\hline Spot no. & NCBI GI no. & protein name & $\begin{array}{c}\text { Mowse } \\
\text { score }\end{array}$ & $\begin{array}{c}\text { Sequence } \\
\text { coverage (\%) }\end{array}$ & Mascot Pi & $\begin{array}{c}\text { Mascot Mw } \\
(\mathrm{kDA})\end{array}$ & $\begin{array}{c}\text { Fold } \\
\text { Peptides no. } \\
\text { difference }\end{array}$ \\
\hline s11 & 118766754 & B-tubulin & 332.729 & 18.01 & 5.62 & 41.48 & 12 \\
s29 & 118084001 & Peroxiredoxin 4 & 7.72 & 13.21 & 6.28 & 29.62 & 3 \\
s30 & 115391986 & UCHL1 & 88.54 & 9.40 & 5.81 & 25.21 & 2 \\
\hline
\end{tabular}

UCHL1, ubiquitin carboxyl-terminal hydrolaseL1

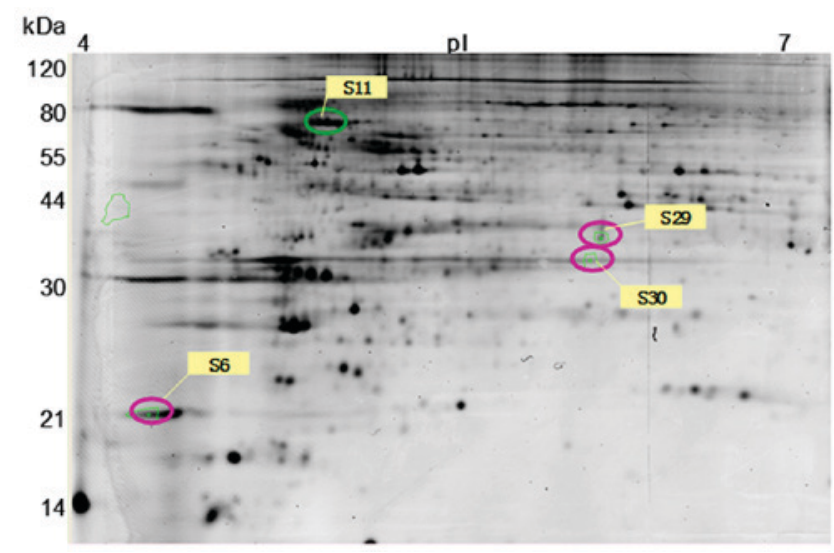

Figure 3. Identification of differential protein expression in myopia early recovery retinas and control retinas by Pro-Q Diamond staining 2D gel electrophoresis. The gel image is a representative Pro-Q Diamond staining gel. Approximate molecular weights and isoelectric points are indicated. Spots in red indicate upregulated proteins, while those in green are downregulated proteins in myopia recovery retinas.

\section{Discussion}

Our results indicated that short-term myopia was reversible after minus lens removal, as shown by the axial vitreous chamber length, although choroidal thickness changed in an opposite direction to axial length. These results were in accordance with previous reports (22-27).

DIGE has introduced an internal control, and has a relatively high resolution. The internal standard paradigm in DIGE allows a precise comparison within and across treatment groups, thus displaying new proteins despite their quantity alterations as a consequence of the comparison (28). Samples are labelled using different fluorescent dyes, mixed and resolved on a single $2 \mathrm{D}$ gel. The fluorescence-based technique has also an advantage of a broad linear dynamic range of $10^{4}$, allowing the detection of slight changes in protein expression as low as $10 \%$, with a confidence level of $95 \%$ (29-31).

Previous studies revealed that Rab family proteins possess a regulatory role in membrane transport, which is essential for developmental processes $(32,33)$. Indeed, Rab11 is essential for Drosophila eye development and embryogenesis, since Rab11 endosomes control vesicle exocytosis and membrane growth in the cellularization process $(34,35)$. Rab11 family-interacting protein 4 (Rab11-FIP4) is mainly expressed in neural tissues, playing a role in zebra fish and mouse retinal development $(36,37)$. Rab11 is also important in the transport of other rhabdomeric proteins, such as transient receptor potential (TRP) channel, which is a light-activated $\mathrm{Ca}^{2+}$ channel working in phototransduction (38). From the above reports, we might conclude that Rab11 is required for the formation of endosomal multivesicular bodies in rhabdomeres, and might have a role in the traffic of rhabdomeric membranes.

Arrestin inhibits the activated phototransduction cascade, although the inhibitory effect mechanism is still not well-known (39). An accepted hypothesis is that arrestin binds to the phosphorylated and photoexcited rhodopsin, thus quenching the light-dependent cGMP-phosphodiesterase activation, or it may directly act on inhibiting cGMP-phosphodiesterase activation $(40,41)$. Additionally, arrestin exerts an inhibitory activity on rhodopsin phosphatase (42). Our results showed that arrestin was upregulated in the myopic recovery retinas, suggesting that it might play a role in desensitizing the photoactivated transduction cascade and it may be consequently involved in the occurrence and recovery of myopia. 
PSMD14, a 2.5-MDa protein, exerts an important role in the ubiquitin proteasome system. Indeed, it removes impaired proteins, as well as those no longer required (43-45). Although, humans possess several non-ATPase subunits, few of them have been cloned and sequenced, but their roles remain unclear. However, the S14 unit is a NIN1 homologue, which is a yeast gene involved in the cell cycle, encoding for a protein necessary for both G1/S and G2/M transitions (46). According to our results, PSMD14 was upregulated in the recovering myopic retinas, suggesting that in the process of myopia development and recovery, tissue metabolism was active, as a remarkable amount of metabolic waste was produced and this protein was acting as a scavenger.

The proteins whose expression was modified, belonged to the categories 'metabolic' and 'protein degradation and apoptosis', suggesting that they might have several different roles in retinal signal processing during the development of myopia and its recovery after lens removal. Although 2D-DIGE studies mostly focused on analyzing native retina protein profiles, PTM results were also crucial in determining several protein functions, such as cell differentiation, cell cycle control, and signal transduction $(47,48)$. More than 200 different PTM types have been described, but not all of them are relevant in the biological process regulation: Protein phosphorylation is one of the most studied PTM (49).

Tubulins have been shown to exert significant roles in eye development. Tubulin $\alpha-1$ chain may impart a 'GO/GROW' signal for myopia in chicken retinas (50). In contrast, tubulin downregulation, such as tubulin $\alpha-2$ and tubulin $\alpha-6$, may correspond to a decreased cell and internal organelle movement during sclera remodeling (3). Furthermore, tubulin $\alpha-3$ seems to be involved in keratoconus, a human corneal non-inflammatory disease, resulting in myopia and astigmatism and it is considered as a neuromarker due to its presence in developing retina (51-53). Our results revealed a decrease in phosphorylation activity of $\beta$-tubulin in the retina of myopia recovery eyes, suggesting a role of the retina in the decreased scleral remodeling activity in myopia recovery group.

Peroxiredoxin 4 is a cytoplasmic or organellar anti-oxidative enzyme involved in intracellular redox signaling and gene transcription $(54,55)$. Guinea pigs' sclera proteomic analysis showed that peroxiredoxin 4 was decreased in the monocular deprivation eyes (3). Tree shrew sclera proteomic study also found a decrease in peroxiredoxin 4 levels during lens-induced myopia (13). In the present study, peroxiredoxin 4 phosphorylation activity increased in the myopia recovery eye, suggesting the presence of many oxidation products. Since peroxiredoxin 4 decreases oxidative stress through hydrogen peroxide reduction in a thiol-dependent catalytic cycle, the increase of this protein might suggest an increased protective effect (56).

UCHL1 is considered a neuron-specific protein (57). A recent report demonstrated that UCHL1 silencing resulted in a reduction of both cell proliferation and migration in human retinal endothelial cells from human corpses (58). Since UCHL1 is a deubiquitinating enzyme, their results suggest that its silencing may inhibit neovascularization, thus indicating UCHL1 involvement in proliferation, migration and neovascularization within the retina. Although they conclude their work suggesting a role of UCHL1 in neovascular eye diseases, our results showing an UCHL1 increase in the retina of a myopia recovering chick eye might indicate its potential role in regulating retinal rearrangement in the recovery eye.

Although a recent study demonstrated the potential involvement of oxidative stress and lipid metabolism in ocular eye growth (59), no differentially expressed proteins related to these pathways were found in the current results. Apolipoprotein A1 (ApoA1) is suggested to act as a 'STOP' signal in the myopia development (50). ApoA1 also acts as a retinoic acid-binding protein secreted by the choroid and sclera during eye growth (60). However, we did not find any ApoA1 upregulation in the recovering myopic retina. The underlying reason could be that different ocular tissues have been studied and different techniques have been employed. In addition, our study mainly focused on the expression of soluble proteins within the $\mathrm{pH}$ 4-7 range (in Pro-Q Diamond phosphoprotein staining 2D gel electrophoresis) and the $\mathrm{pH} 5-8$ range (in 2D-DIGE), in which only part of the retinal proteins can be resolved. This is a very different approach than the ones used in the two cited studies. Moreover, Yu et al (59) studied protein regulation in the vitreous instead of in the retina as was done in our work. Hence, the entire retinal proteome in this study could not be visualized. Furthermore, during early active growth, great inter-animal variations in retinal proteins could be present. In order to decrease the inter-animal variations, we used both eyes in each chick and we only chose the differentially expressed proteins detected in all chicks and in the same change direction. Therefore, this study did not describe all the differences in retinal proteins during the myopia recovery process and purposely excluded those proteins that failed to repeat in all chicks. Although this method can minimize false positive results, some potentially important proteins such as ApoA1 can be missed. On the other hand, in this study the control eye is not a myopic eye but a paired 'normal' eye. As a result, some of the proteins which increased (or decreased) during myopia process but decreased (or increased) during the myopia recovery process are missed. The initial protein increase (or decrease) can be partly counteracted by the following protein decrease (or increase), thus, the total change is very small and might not be detected. Our study firstly focused on those most significant and repeatable differences in proteins not only in their abundance but also their PTMs in the myopic recovery retina. Although the actual number of proteins that were regulated was likely to be under-estimated in this study, the differentially expressed proteins reported are helpful for generating hypotheses that can unravel the biochemical mechanisms implicated in myopia early recovery.

In our present study, we did not perform confirmation of the proteomics results by conventional western blot or gene expression because of the relatively low fold changes of differentially expressed proteins we found. Poorer consistency in quantification and limited antibodies for chicks are two typical technical constrains for confirming MS data, which is more robust, accurate, reproducible and achieving low limits of detection (61). As regard gene expression, more recent studies on microarray and RNA sequencing have indicated that mRNA levels may not be accurate as surrogates for corresponding protein levels as mRNA levels do not usually predict the corresponding protein levels (62-64). Hannis weighs PCR 
amplicons using MS and obtained accurate protein results to unambiguously determine the base composition of each amplicon, and not the other way around, that is, using PCR to confirm MS results (65). Hence, our further direction is trying to apply multiple reactions monitoring (MRM) MS as an alternative approach to conventional western blot analysis. This targeted approach was reported as a next-generation platform overcoming many of the limitations of western blotting, providing new prospects for protein analysis (20). Once the setup is established, we may run MS-based validation on protein level.

Overall, our results suggested that retinal proteomics and its related characterization could be useful in the discovery of biomarkers. The observed differences in protein expression between groups revealed proteins that are potentially involved in myopia early recovery, which might be important in developing strategies to counteract myopia.

\section{Acknowledgements}

Not applicable.

\section{Funding}

The present study was supported by The Hong Kong Polytechnic University (grant nos. GUA32, GYK89, RGC-GRF-PolyU 151051/17M, 151033/15M, Strategic Area of Importance-1ZE1A, PolyU Research Fund GYBBU and GYBQU) and the Henry G Leong Professorship in Elderly Vision Health.

\section{Availability of data and materials}

All data generated or analyzed during this study are included in this published article.

\section{Authors' contributions}

YYZ wrote the manuscript and performed the experiments. RKMC supervised the entire work and critically revised the manuscript, analyzed and interpreted the data and had final approval of the manuscript. JCW and BZ collected the results and drafted the manuscript. KKL analyzed and interpreted the results and supervised the entire work. TCL analyzed and interpreted the results and critically revised the manuscript. QL and CHT designed the experiments and approved the final version of the manuscript.

\section{Ethics approval and consent to participate}

The experimental procedure and protocols were approved by the Animal Ethics Approval Committee of the Hong Kong Polytechnic University.

\section{Consent for publication}

Not applicable.

\section{Competing interests}

The authors declare that they have no competing interests.

\section{References}

1. Norton TT, Amedo AO and Siegwart JT Jr: The effect of age on compensation for a negative lens and recovery from lens-induced myopia in tree shrews (Tupaia glis belangeri). Vision Res 50: 564-576, 2010.

2. Smith EL III, Hung LF, Arumugam B and Huang J: Negative lens-induced myopia in infant monkeys: Effects of high ambient lighting. Invest Ophthalmol Vis Sci 54: 2959-2969, 2013.

3. Zhou X, Ye J, Willcox MD, Xie R, Jiang L, Lu R, Shi J, Bai Y and $\mathrm{Qu} \mathrm{J}$ : Changes in protein profiles of guinea pig sclera during development of form deprivation myopia and recovery. Mol Vis 16: 2163-2174, 2010 .

4. Shen W and Sivak JG: Eyes of a lower vertebrate are susceptible to the visual environment. Invest Ophthalmol Vis Sci 48: 4829-4837, 2007.

5. Wallman J and Winawer J: Homeostasis of eye growth and the question of myopia. Neuron 43: 447-468, 2004.

6. Zee BM and Garcia BA: Discovery of lysine post-translational modifications through mass spectrometric detection. Essays Biochem 52: 147-163, 2012.

7. Eichler J and Maupin-Furlow J: Post-translation modification in Archaea: Lessons from Haloferax volcanii and other haloarchaea. FEMS Microbiol Rev 37: 583-606, 2013.

8. Mann M and Jensen ON: Proteomic analysis of post-translational modifications. Nat Biotechnol 21: 255-261, 2003.

9. Petrov D, Margreitter C, Grandits M, Oostenbrink C and Zagrovic B: A systematic framework for molecular dynamics simulations of protein post-translational modifications. PLoS Comput Biol 9: e1003154, 2013.

10. Zolnierowicz S and Bollen M: Protein phosphorylation and protein phosphatases. De Panne, Belgium, September 19-24, 1999. EMBO J 19: 483-488, 2000.

11. Zhu X, McBrien NA, Smith EL III, Troilo D and Wallman J: Eyes in various species can shorten to compensate for myopic defocus. Invest Ophthalmol Vis Sci 54: 2634-2644, 2013.

12. Frost MR and Norton TT: Differential protein expression in tree shrew sclera during development of lens-induced myopia and recovery. Mol Vis 13: 1580-1588, 2007.

13. Frost MR and Norton TT: Alterations in protein expression in tree shrew sclera during development of lens-induced myopia and recovery. Invest Ophthalmol Vis Sci 53: 322-336, 2012.

14. Amedo AO and Norton TT: Visual guidance of recovery from lens-induced myopia in tree shrews (Tupaia glis belangeri). Ophthalmic Physiol Opt 32: 89-99, 2012.

15. Wang JC, Chun RK, Zhou YY, Zuo B, Li KK, Liu Q and To CH: Both the central and peripheral retina contribute to myopia development in chicks. Ophthalmic Physiol Opt 35: 652-662, 2015.

16. Chun RK, Shan SW, Lam TC, Wong CL, Li KK, Do CW and To $\mathrm{CH}$ : Cyclic adenosine monophosphate activates retinal apolipoprotein A1 expression and inhibits myopic eye growth. Invest Ophthalmol Vis Sci 56: 8151-8157, 2015.

17. Lam TC, Li KK, Lo SC, Guggenheim JA and To CH: A chick retinal proteome database and differential retinal protein expressions during early ocular development. J Proteome Res 5: 771-784, 2006.

18. Lam TC, Li KK, Lo SC, Guggenheim JA and To CH: Application of fluorescence difference gel electrophoresis technology in searching for protein biomarkers in chick myopia. J Proteome Res 6: 4135-4149, 2007.

19. Wu Y, Liu Q, To C, Li K, Chun R, Yu J and Lam T: Differential retinal protein expressions during form deprivation myopia in albino guinea pigs. Curr Proteomics 11: 37-47, 2014.

20. Liebler DC and Zimmerman LJ: Targeted quantitation of proteins by mass spectrometry. Biochemistry 52: 3797-3806, 2013.

21. Tu C, Beharry KD, Shen X, Li J, Wang L, Aranda JV and Qu J: Proteomic profiling of the retinas in a neonatal rat model of oxygen-induced retinopathy with a reproducible ion-current-based MS1 approach. J Proteome Res 14: 2109-2120, 2015.

22. Hung LF, Wallman J and Smith EL III: Vision-dependent changes in the choroidal thickness of macaque monkeys. Invest Ophthalmol Vis Sci 41: 1259-1269, 2000.

23. Liang H, Crewther SG, Crewther DP and Junghans BM: Structural and elemental evidence for edema in the retina, retinal pigment epithelium, and choroid during recovery from experimentally induced myopia. Invest Ophthalmol Vis Sci 45: 2463-2474, 2004.

24. Lu F, Zhou X, Jiang L, Fu Y, Lai X, Xie R and Qu J: Axial myopia induced by hyperopic defocus in guinea pigs: A detailed assessment on susceptibility and recovery. Exp Eye Res 89: 101-108, 2009. 
25. Nickla DL, Zhu X and Wallman J: Effects of muscarinic agents on chick choroids in intact eyes and eyecups: Evidence for a muscarinic mechanism in choroidal thinning. Ophthalmic Physiol Opt 33: 245-256, 2013.

26. Rada JA and Palmer L: Choroidal regulation of scleral glycosaminoglycan synthesis during recovery from induced myopia. Invest Ophthalmol Vis Sci 48: 2957-2966, 2007.

27. Wildsoet C: Neural pathways subserving negative lens-induced emmetropization in chicks-insights from selective lesions of the optic nerve and ciliary nerve. Curr Eye Res 27: 371-385, 2003.

28. Ferrin G, Ranchal I, Llamoza C, Rodríguez-Perálvarez ML, Romero-Ruiz A, Aguilar-Melero P, López-Cillero P, Briceño J, Muntané J, Montero-Álvarez JL and De la Mata M: Identification of candidate biomarkers for hepatocellular carcinoma in plasma of HCV-infected cirrhotic patients by 2-D DIGE. Liver Int 34 438-446, 2014.

29. Knowles MR, Cervino S, Skynner HA, Hunt SP, de Felipe C Salim K, Meneses-Lorente G, McAllister G and Guest PC: Multiplex proteomic analysis by two-dimensional differential in-gel electrophoresis. Proteomics 3: 1162-1171, 2003.

30. Marouga R, David S and Hawkins E: The development of the DIGE system: 2D fluorescence difference gel analysis technology. Anal Bioanal Chem 382: 669-678, 2005.

31. Wu TL: Two-dimensional difference gel electrophoresis Methods Mol Biol 328: 71-95, 2006

32. Fukuda M: Regulation of secretory vesicle traffic by Rab small GTPases. Cell Mol Life Sci 65: 2801-2813, 2008.

33. Khvotchev MV, Ren M, Takamori S, Jahn R and Südhof TC: Divergent functions of neuronal Rab11b in $\mathrm{Ca}^{2+}$-regulated versus constitutive exocytosis. J Neurosci 23: 10531-10539, 2003.

34. Alone DP, Tiwari AK, Mandal L, Li M, Mechler BM and Roy JK Rab11 is required during Drosophila eye development. Int J Dev Biol 49: 873-879, 2005.

35. Pelissier A, Chauvin JP and Lecuit T: Trafficking through Rab11 endosomes is required for cellularization during Drosophila embryogenesis. Curr Biol 13: 1848-1857, 2003.

36. Muto A, Aoki Y and Watanabe S: Mouse Rab11-FIP4 regulates proliferation and differentiation of retinal progenitors in a Rab11-independent manner. Dev Dyn 236: 214-225, 2007.

37. Muto A, Arai K and Watanabe S: Rab11-FIP4 is predominantly expressed in neural tissues and involved in proliferation as well as in differentiation during zebrafish retinal development. Dev Biol 292: 90-102, 2006

38. Ng EL and Tang BL: Rab GTPases and their roles in brain neurons and glia. Brain Res Rev 58: 236-246, 2008.

39. Zhu X, Li A, Brown B, Weiss ER, Osawa S and Craft CM: Mouse cone arrestin expression pattern: Light induced translocation in cone photoreceptors. Mol Vis 8: 462-471, 2002.

40. Palczewski K, Pulvermüller A, Buczyłko J and Hofmann KP Phosphorylated rhodopsin and heparin induce similar conformational changes in arrestin. J Biol Chem 266: 18649-18654, 1991.

41. Zipfel B, Schmid HA and Meissl H: Photoendocrine signal transduction in pineal photoreceptors of the trout. Role of cGMP and nitric oxide. Adv Exp Med Biol 460: 79-82, 1999.

42. Palczewski K, McDowell JH, Jakes S, Ingebritsen TS and Hargrave PA: Regulation of rhodopsin dephosphorylation by arrestin. J Biol Chem 264: 15770-15773, 1989.

43. Finley D: Recognition and processing of ubiquitin-protein conjugates by the proteasome. Annu Rev Biochem 78: 477-513, 2009.

44. Murata S, Yashiroda H and Tanaka K: Molecular mechanisms of proteasome assembly. Nat Rev Mol Cell Biol 10: 104-115, 2009.

45. Tanaka K: The proteasome: Overview of structure and functions Proc Jpn Acad Ser B Phys Biol Sci 85: 12-36, 2009.

46. Kominami K, DeMartino GN, Moomaw CR, Slaughter CA, Shimbara N, Fujimuro M, Yokosawa H, Hisamatsu $H$, Tanahashi N, Shimizu Y, et al: Ninlp, a regulatory subunit of the $26 \mathrm{~S}$ proteasome, is necessary for activation of Cdc28p kinase of Saccharomyces cerevisiae. EMBO J 14: 3105-3115, 1995.

47. Lee S: Post-translational modification of proteins in toxicological research: Focus on lysine acylation. Toxicol Res 29: 81-86, 2013

48. Xu Y, Wang X, Wang Y, Tian Y, Shao X, Wu LY and Deng N: Prediction of posttranslational modification sites from amino acid sequences with kernel methods. J Theor Biol 344: 78-87, 2014.
49. Axelsen LN, Calloe K, Holstein-Rathlou NH and Nielsen MS: Managing the complexity of communication: Regulation of gap junctions by post-translational modification. Front Pharmacol 4 $130,2013$.

50. Bertrand E, Fritsch C, Diether S, Lambrou G, Müller D, Schaeffel F, Schindler P, Schmid KL, van Oostrum J and Voshol H: Identification of apolipoprotein A-I as a 'STOP' signal for myopia. Mol Cell Proteomics 5: 2158-2166, 2006.

51. McKerracher L, Essagian C and Aguayo AJ: Marked increase in beta-tubulin mRNA expression during regeneration of axotomized retinal ganglion cells in adult mammals. J Neurosci 13 5294-5300, 1993

52. Nielsen K, Birkenkamp-Demtröder K, Ehlers N and Orntoft TF: Identification of differentially expressed genes in keratoconus epithelium analyzed on microarrays. Invest Ophthalmol Vis Sci 44: 2466-2476, 2003

53. Sharma RK, O'Leary TE, Fields CM and Johnson DA: Development of the outer retina in the mouse. Brain Res Dev Brain Res 145: 93-105, 2003.

54. Wagner E, Luche S, Penna L, Chevallet M, Van Dorsselaer A, Leize-Wagner E and Rabilloud T: A method for detection of overoxidation of cysteines: Peroxiredoxins are oxidized in vivo at the active-site cysteine during oxidative stress. Biochem J 366 : 777-785, 2002

55. Wong CM, Chun AC, Kok KH, Zhou Y, Fung PC, Kung HF, Jeang KT and Jin DY: Characterization of human and mouse peroxiredoxin IV: Evidence for inhibition by Prx-IV of epidermal growth factor- and p53-induced reactive oxygen species. Antioxid Redox Signal 2: 507-518, 2000

56. Wood ZA, Schröder E, Robin Harris J and Poole LB: Structure, mechanism and regulation of peroxiredoxins. Trends Biochem Sci 28: 32-40, 2003 .

57. Day IN and Thompson RJ: UCHL1 (PGP 9.5): Neuronal biomarker and ubiquitin system protein. Prog Neurobiol 90: 327-362, 2010.

58. Pan Y, Appukuttan B, Mohs K, Ashander LM and Smith JR: Ubiquitin carboxyl-terminal esterase L1 promotes proliferation of human choroidal and retinal endothelial cells. Asia Pac J Ophthalmol (Phila) 4: 51-55, 2015.

59. Yu FJ, Lam TC, Liu LQ, Chun RK, Cheung JK, Li KK and To CH: Isotope-coded protein label based quantitative proteomic analysis reveals significant up-regulation of apolipoprotein A1 and ovotransferrin in the myopic chick vitreous. Sci Rep 7: 12649, 2017.

60. Summers JA, Harper AR, Feasley CL, Van-Der-Wel H, Byrum JN, Hermann M and West CM: Identification of apolipoprotein A-I as a retinoic acid-binding protein in the eye. J Biol Chem 291: 18991-19005, 2016.

61. Aebersold R, Burlingame AL and Bradshaw RA: Western blots versus selected reaction monitoring assays: Time to turn the tables? Mol Cell Proteomics 12: 2381-2382, 2013.

62. Lundberg E, Fagerberg L, Klevebring D, Matic I, Geiger T, Cox J, Algenäs C, Lundeberg J, Mann M and Uhlen M: Defining the transcriptome and proteome in three functionally different human cell lines. Mol Syst Biol 6: 450, 2010.

63. Schwanhäusser B, Busse D, Li N, Dittmar G, Schuchhardt J, Wolf J, Chen W and Selbach M: Global quantification of mammalian gene expression control. Nature 473: 337-342, 2011.

64. Vogel C, Silva GM and Marcotte EM: Protein expression regulation under oxidative stress. Mol Cell Proteomics 10: M111 009217, 2011.

65. Hannis JC, Manalili SM, Hall TA, Ranken R, White N, Sampath R, Blyn LB, Ecker DJ, Mandrell RE, Fagerquist CK, et al: High-resolution genotyping of Campylobacter species by use of PCR and high-throughput mass spectrometry. J Clin Microbiol 46: 1220-1225, 2008.

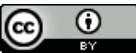

This work is licensed under a Creative Commons Attribution 4.0 International (CC BY 4.0) License. 